\title{
The axiological foundations of freedom phenomen: a socio-philosophical reality
}

\author{
Aralkhanov Baglan - Maldybek Akmaral - Amangeldiyev Assan - \\ Almazbek Beishenaliev - Yessim Garifolla
}

DOI: $10.18355 / X L .2022 .15 .01 .08$

\begin{abstract}
This article analyzes and summarizes the results of historical, philosophical, and general scientific research related to the topic of freedom. The main components of the philosophical foundations of freedom that exist in the general scientific and philosophical literature are highlighted. The specificity of the problem of freedom in the context of activity theory is emphasized. The content, denotation, and axiological significance of the term "freedom management" are determined. For the first time, a synthesis of activity-based and synergetic approaches was applied to the analysis of freedom, which made it possible to analyze freedom at both the "micro" and "macrotheoretical" levels. The advantages of applying the synergetic approach to the analysis of the problem of freedom as the ability to determine the boundaries of the possible in a complex, non-linear, multivariate movement to the ideal image of the future state of the system are shown. It is shown that the measure of freedom of the subject is mainly determined by the measure of approximation to the ideal, the desire for extreme proximity to it, and as a result, the acquisition of a state of harmony. An analysis of the concepts of "freedom management" is made, and an activity-based approach is applied to the analysis of this phenomenon, which allows us to consider the concept of "freedom management" as one of the restrictions on freedom.
\end{abstract}

Key words: freedom, ethics, morality, religion, philosophy, reason, truth, God, ideal, good

\section{Introduction}

To date, the questions of the axiological foundations of freedom are among the most important problems of social philosophy. Turning to the study of this problem allows us to determine the possibilities of realizing a person as a unique creation through the definition of the nature of freedom, how it is constructed, and how it functions in the conditions of a particular social structure. At each new stage of its historical development, humanity solves the problem of freedom in a new way, depending on the level of development of culture and science, the dominant values, ideals, and ideas. The degree of freedom depends on the immediate conditions in which the activity is carried out (Sen, 2004).

The study of the modern concept of freedom is very relevant since the sociophilosophical analysis using different strategies of cognition helps solve the problem of freedom at a new level. It makes it possible to rethink it in the conditions of fundamentally new forms of spiritual, political, economic, and technical-technological orders. The concept of "freedom" is polysemantic, which, admittedly, excludes the possibility of there being the only "correct" scientific definition. Being an integral phenomenon of human existence, the problem of freedom is the object of attention not only of scientific-practical and scientific-theoretical but also of everyday-practical knowledge.

The problem of freedom concerns not only philosophy but also many other scientific disciplines: sociology, political science, psychology, economics, ethics, etc. However, these disciplines are interested neither in freedom as a social phenomenon nor its essence, but from the point of view of its application, concrete content, manifestation,

XLinguae, Volume 15 Issue 1, January 2022, ISSN 1337-8384, eISSN 2453-711X 
and influence on reality, both on society as a whole and the individual. It is worth noting that the definition of the concept of "freedom" varies even within one scientific discipline. For example, in philosophy, freedom is defined differently, depending on the specific philosophical position that the researcher takes (materialistic or idealistic). What remains common is one philosophical question: how is it possible, and is it even possible, to achieve true freedom? (Hayek, 2006).

As a rule, everyone has a subjective everyday idea of what freedom is, since this concept belongs to the number of universal categories that have the highest value for a person. Complicating the situation is the lack of a single definition of the concept of "freedom" and the fact that it is constantly mentioned in the media and political debates, gradually losing its true meaning and value, often becoming the object of speculation. Perhaps that is why at the end of the $20^{\text {th }}$ century, during the formation of the information society, philosophy faced a number of questions that have not lost their relevance to this day. What changes in society occur under the influence of information? What role does the media play in these changes? Is it possible to manage mass behavior and mass consciousness? Is such governance violent, or does the individual's freedom remain unshaken?

It is worth mentioning the relatively recent but already popular expression "management of freedom," which implies the possibility and the active implementation of managerial influence on a person in his daily life. As a confirmation of the existence of the phenomenon of "freedom management," examples are given of advertising campaigns that achieve their goals (buying goods by a person without a real need for it), or voting in political elections for a candidate in which a person is not really interested. Indeed, there are many examples of such situations, but does all of this constitute sufficient evidence that a person is thereby deprived of freedom? It is choice, freedom of choice, that is the essential characteristic of a person's life position, and the socio-philosophical interpretation of the problem of freedom of choice has a great theoretical potential that can put all the dots over the "I" in this issue. The solution to the problem of individual freedom lies in defining the boundaries of freedom. Only a person who makes and implements his choice can be called free while being aware of his responsibility for it (Brambo, 2002).

\section{Research methods}

The use of new scientific methods and approaches of theoretical and practical study allows us to solve the problem of freedom in philosophy in a new way, to clarify the scientific definition of the concept itself in the spirit of modern realities. A characteristic feature of modern humanities and social sciences is non-linear thinking, which allows us to study human activity in its subjective cultural and psychological coordinates, taking into account alternative scenarios. It is no longer enough for a synergistically thinking philosopher to study a particular phenomenon, directly linking the previous and subsequent states. He must take into account the probability of the course of events when making an alternative choice. The place of freedom in the process of non-linear evolution, in the self-organization of social systems, seems to us uniquely relevant for understanding the processes taking place in the modern world. In this regard, the application of a synergetic approach to solving the problem of freedom is necessary for modern scientific knowledge.

The insufficient development of the socio-philosophical aspects of the abovementioned problems and the need for a socio-philosophical understanding of general philosophical and general scientific ideas about freedom justify the topic of this paper's research. (Levitsky, S. A., 2011) The literature devoted to this problem is truly immense. The problem of freedom is raised and solved in its own way in the works of many philosophers of various schools and directions. The historical chronology of the study of the problem of freedom is represented by the works of 
thinkers, such as Heraclitus, Socrates, Plato, Aristotle, etc. (in Antiquity), Descartes, B. Spinoza, G. Leibniz, etc. (in the Middle Ages and early Modern times), J.-J. Rousseau, etc. (in the Age of Enlightenment), I. Kant, I. G. Fichte, F. Schelling, G. Hegel (in German classical philosophy), NA. Berdyaev, N. O. Lossky, etc. (in Western European philosophy of the $19^{\text {th }}-20^{\text {th }}$ centuries, representatives of Russian philosophy).

Modern mass society has its own specifics, particularly a strong relationship between the problems of freedom and alienation, as a person is increasingly alienated from the world and himself, thereby losing touch with his being. Such philosophers as K. Marx, H. Ortega y Gasset, M. Heidegger, G. Marcuse, E. Fromm, and M. G. Denhoff studied the problems of alienation.

When we turn to the activity approach in the study of freedom, it is necessary to clarify that the activity component of freedom was initially developed in psychological science. (Anthology of Philosophy, 2003) More recently, a synergistic approach has been applied to the analysis of the problem of freedom. The possibility and undoubted benefit of applying this approach to the study of human activity stem from the nature of its relationship with the surrounding reality in methodological terms. The problem of governance, as well as the problem of freedom, is quite extensively presented in the literature. However, few authors pay attention to both the specifics and the possibility of a general relationship and even interdependence of these phenomena. Only a few works of researchers such as V. P. Pugachev and E. V. Vyazova are devoted to the analysis of the relationship between freedom and management in the field of management. No one has yet addressed the philosophical understanding of the phenomenon of "freedom management."

When studying this problem, there are certain trends in understanding the problem of freedom. On the one hand, the understanding of the complexity, non-linearity, uncertainty of the development of both natural and social reality increases; on the other hand, the uncertainty, incompleteness, and relevance of the philosophical understanding of the problem of freedom reveals itself in the process. Despite the centuries-old history of studying the problem of freedom by classical and modern philosophical thought, both domestic and foreign, a holistic view of the phenomenon under study has not yet been formed. Our research, of course, does not claim to be able to solve the essentially global problem of freedom, but the work done can serve as a certain step forward in the study of freedom in the realities of modern life.

The methodological basis of the axiological foundations of freedom is the historicalmaterialistic approach to comprehensive analysis. The solution of the problems studied in this paper is carried out in line with the system-activity approach using the principles of ascent from the abstract to the concrete, the unity of historical and logical, the principle of determinism, as well as general scientific principles of cognition of social phenomena. The foundations of freedom appear as the genesis of views and models of knowledge of the problem of freedom in the history of philosophy. The philosophical understanding of the problem of freedom appears as an infinite variety of different approaches to its solution, where freedom appears in different guises and combinations, from necessity and even slavery to its convergence with choice and equating it with a will. The solution to the problem of freedom depends on the specifics of a particular society, its practical needs, the level of development of science and culture, the type of sociality, etc.

Let us consider the models of knowledge of freedom in chronological order (Losev, 2009). A person of tribal society thought of freedom exclusively as belonging to a clan, a tribe. Freedom from the race was inconceivable during this period since becoming an outcast meant that that person died. In Antiquity (Heraclitus, Democritus, Socrates, Plato, Aristotle, Epicurus, the Stoics, etc.), freedom did not stand out as a separate philosophical problem. This does not mean that it was not

XLinguae, Volume 15 Issue 1, January 2022, ISSN 1337-8384, eISSN 2453-711X 
discussed. The term "freedom" itself, of course, was used quite often, but mainly in connection with the real life of city-states. Ancient thinkers recognized the opposite of a free man and a slave. At the same time, real freedom was considered a privilege of some (those who have power over others, adequate knowledge, morality, etc.). The conceptualization of freedom was usually associated with an emphasis on its relationship with the concepts of "necessity" and "fate," which embodies a supernatural or religious necessity external to a person. The fatalistic position in Antiquity is represented by such thinkers as Heraclitus, Democritus, Aristotle, and Socrates. As such, there was no human problem at the naturalistic stage of ancient philosophy. The main attention of philosophers was paid to the knowledge of nature and the cosmos. However, we can find individual thoughts of representatives of this period regarding man and his freedom.

Thus, according to Heraclitus, man is completely determined by fate: "... everything happens according to the determination of fate, the latter is identical with necessity." An all-powerful fate predetermines any action of a person; it is impossible to understand and predict its plan (i.e., fate) in advance, which is why a person is always in the dark about his future.

Democritus also held the view that there is no free will of man. He argued that the world of atoms is totally dominated by necessity, which for him is identical with causality: everything that is causally conditioned is necessary. Everything bad that happens to a person is the result of a lack of necessary knowledge; therefore, the elimination of problems is possible only through the acquisition of knowledge. The main goal of human existence for Democritus was to find it in a state of serene mood without passions and extremes, in a state of peace, serenity, and harmony.

The humanistic stage of ancient philosophy, represented by the sophists and Socrates, is characterized by a focus on the problem of man and his life as a member of society. At the same time, the cosmology of the naturalistic period takes a back seat (Diogenes, 2009). Socrates was the first in the history of philosophy to attempt to define the essence of man. Socrates' teaching, and, in particular, the solution to the problem of freedom, is based on the concepts of "knowledge." Knowledge is the prerequisite of the moral, and true morality is the knowledge of the good. For Socrates, the concepts of "knowledge" and "morality" are inseparable from each other since a person who has learned what is good and evil will no longer act differently than his knowledge and reason tell him. The manifestation of the superiority of reason, according to Socrates, is self-control as power over oneself in states of joy, sadness, etc. Self-control is the power of reason over instinct. Thus, a truly free person, as opposed to a slave, is a person who knows how to control his instincts and does it. Plato, the founder of objective idealism, distinguished between the world of ideas (real existence) and the material world (the world of shadows). Things are the shadow of ideas, which act as a kind of model of all surrounding things, unchangeable, immovable, and eternal, while the things of the material world arise and perish constantly. The material world is known by the senses. The mind does not comprehend individual things, only the corresponding entities, that is, the ideas that form the basis of things. Thus, ideas are genuine entities that are outside the material world. On the other hand, knowledge is not a sensation, a correct opinion, or a combination of a correct opinion with meaning since it is a "penetration" into the world of ideas, where memory plays an important role. Plato drew a clear line between knowledge (knowledge of ideas), which leads to absolute truth, and opinion (the sense world), which concerns only the external surface of things. The freedom of man presupposes the obligatory rational participation of his soul in the world of ideas. The task of man is to subdue the unintelligent parts of his soul to the rational part of his soul and also to tame his evil aspirations. Thus, Plato developed the doctrine of expediency, according to which everything that exists in the world strives to achieve the good as the ultimate goal. In work "The State," Plato proposes to distinguish the 
existing types of society by the moral qualities and characteristics of the individuals they are represented by. Without going into details, we note that democracy was defined by Plato as a bad version of the state system since people, improperly disposing of their freedom, which had been given to them by the Gods, ultimately led the state to tyranny (the worst option). And a tyrant is a person who has given himself unlimited freedom while denying responsibility for his actions.

Just like Plato, Aristotle sees the highest good for a man not in sensual pleasures or material goods but in spiritual satisfaction. It is such a state of mind that arises from a sense of fulfilled duty, the realization of a person's purpose. The purpose of man consists in the self-improvement and self-affirmation of his personality as a spiritual being through the domination of reason over the sensuality and lust of man. Aristotle approaches the analysis of man and his morality from the position that a citizen does not exist outside of society. Instead, he is an exclusively socio-political being. The mind is the basis of any human activity, including cognitive. It constitutes the true essence of a person, a distinctive feature of his life and personality. Thanks to the faculty of thinking, a person can make the right choice of their actions and actions, striving to achieve happiness and realize the ethical ideal. The goal of thinking is not knowledge but actions and activities. Since it is not enough to know virtue, it is also necessary to act accordingly, implementing it, as a result of which one becomes a virtuous person. Aristotle insisted that creativity and human activity are different things. Actions are inseparably linked with a person, his activities, and free choice, in accordance with society's general moral and legal norms, while the goal of creativity is to create works of art that are evaluated solely on their merits, regardless of the actions of a person. Moral activity is aimed at the person himself and at the development of the abilities inherent in him (primarily spiritual and moral), at the improvement of his life, and the realization of the meaning of life. In his work "Nicomachean Ethics," Aristotle describes the differences between two types of people: a slave and a free person. A slave by nature is one who cannot think for himself but belongs to another person, following his orders. A free person is a person who is called to control others, and his own body is subject to the dictates of the mind. According to Aristotle, not everyone is able to be free, and not everyone deserves freedom. A free person is a person who is his own creation, and freedom is an attribute of morality. By free choice, a person attains virtue, through which he gets the opportunity to achieve the highest good (happiness). The phenomenon of freedom in Aristotle is essentially related to adequate knowledge (Zizek, 2012).

\section{The problem of the axiological foundations of freedom}

The axiological foundations of the problem of freedom, in our opinion, should be sought in the processes of human anthropo-and sociogenesis since the concept of "freedom" characterizes a specific state of consciousness and activity of a public person. The "positive" concept of freedom as self-possession is based on the premise of the inner "bifurcation" of man into a transcendent master and an empirical bundle of desires and passions that must be controlled.

Let us turn to a man as the bearer of the potencies of freedom. What is a person? To answer this question, let us turn to the structure of being itself, or rather to the theories about its hierarchical structure, that is, in one way or another, claiming that being has a hierarchical structure. This idea was imbued with the metaphysical philosophy of Aristotle. After Aristotle, the complete analysis of the hierarchy of the types of being was given by F. Engels, V. S. Solovyov, N. Hartman, and the supplement with an orientation to the organic worldview was proposed by A. Levitsky. According to Levitsky, ideal and real being are one and have a certain hierarchical structure, including the following types of being:

XLinguae, Volume 15 Issue 1, January 2022, ISSN 1337-8384, eISSN 2453-711X 
- material existence, where matter is considered as "... a kind of sensually perceived reality that exists in space and time and is expressed mathematically." This is the lowest layer of being, in which the approach to stagnation is most pronounced.

- bio-organic existence, which exists on the basis of material existence and is an infinitely complex modification of material processes. Bio-organic being is an organic whole, the structure of which cannot be reduced to the sum of its constituent parts. The organism assumes the presence of both matter and a supermaterial factor, while the matter is the necessary material for the embodiment of the organic form.

- psychic being (spiritual life) is based on material and bio-organic being, but it is a fundamentally new category, has a personal character, characterized by fusion with the human "I". It is not limited to the concepts of causality and expediency. Basically speaking, it is a kind of free creative flow. The spiritual life is composed of sensations, ideas, concepts, etc., and its knowledge is available exclusively to selfobservation. At the same time, the spiritual life is never in a static state. It is rather a continuous stream of changes, which is subject to a changeable rhythm. Thus, there are no two absolutely equal states of mind. In the spiritual life, the past does not die. It is present in the present and participates in the creativity of the future - this is our memory and imagination.

- social existence, like the spiritual life, is not derived from the bio-organic existence but rests on it. Social existence arises from the interaction between individuals and social groups and between groups themselves, thereby forming society as a sphere of activity.

- spiritual existence implies the highest forms of psychic activity. It is "... the domain of cognitive, creative, moral, aesthetic, and mystical acts, the domain of science, art, philosophy, and religion." The spiritual being rises above the soul life, which is above the bio-organic basis, which in turn is above the inorganic matter. In the realm of spiritual existence, the individual goes beyond himself, coming face to face with the world of objective, superpersonal values (cognitive, moral, aesthetic, religious). The spiritual life is free from everything external, spatial, like the soul life, but it is also free from time. Spiritual life is known not by self-observation but by self-experience (Selin, 2009). The dependence of the higher categories of being on the lower ones is not one-sided: the higher categories should not be considered as a "superstructure" over the lower ones since the lower categories are rather the material for the embodiment of the higher ones. The idea of the hierarchical structure of being can be considered a prerequisite for further analysis and understanding of the essence of man in our research.

The concept of "freedom" as a meaningful and not a descriptive category can be used only in relation to a person or a human community since freedom characterizes the specific ability of a person to reflexive consciousness and activity. The presence in philosophical anthropology of four approaches to the definition (in its purest form) of the concept of "man," which is fundamental for conceiving its meaning, makes the matter rather complex. The concepts of "man," "individual," "subject," "personality" all carry specific differences, which makes it difficult to interpret these concepts. Each of the considered approaches absolutizes the influence of a certain layer of being (material, bio-organic, mental, spiritual, and social layers of being) as decisive in determining the essence of a person.

The naturalistic approach to the definition of essence absolutizes the biological aspect and defines the laws of physical nature as determining the meaning of human existence. According to the adherents of this approach, the essence of a person is, first of all, in his initially biological and instinctive nature, which always and everywhere determines his life activity. This methodological approach is one-sided since, by absolutizing the biological aspect of human essence, it almost negates the other qualitative aspects of human existence. In particular, the reasonableness of a person is not taken into account as a necessary condition for activity. 
The theological approach to the definition of the essence of man is based on the doctrine of God. Within the framework of this approach, man is considered as a paradoxical, dual, and contradictory being, which can only be understood in his relation to God as the supreme being. It is argued that it is only in the context of Christian anthropology that it becomes possible to consider man as a spiritual, integral being. God is a kind of center, a core within each person. That is, God comes to a person from within, from the depth, and not from outside. By turning to God, a person can become independent and truly free, and his existence takes on a higher meaning. The disadvantage of this methodological approach is that it can be considered utopian and idealistic since the essence of a person is attributed to the characteristics of the sphere and not of being. In addition, natural and social factors of human development are not taken into account.

The socio-centric approach considers society as the dominant factor that completely determines the life and behavior of a person (Rohrmoser, 2006). The origins of this approach are found in the French materialists of the $18^{\text {th }}$ century. They presented man exclusively as a product of the social environment and upbringing, without considering him an active being. In turn, K. Marx has a slightly different vision of man, for whom this being is active, capable of creating and transforming the environment, and with it its own nature. K. Marx, in his work "Theses on Feuerbach," formulated the basic position of his philosophy as follows: "The essence of man is not an abstract inherent in an individual. In its reality, it is the totality of all social relations." The basis of human life is a collective practical activity since a person is inextricably linked with society. He is its product, and at the same time, defines and changes himself as the whole complex of social relations changes. According to Karl Marx, a person is not born but becomes a social being, changing along with the development of social relations. Thus, the social essence of man is impermanent. A person is not only a product of circumstances and upbringing but also partly his own creation, capable of changing the surrounding social environment. At the same time, he is the same as the social environment surrounding it.

Representatives of social philosophy and sociology of the $19^{\text {th }}-20^{\text {th }}$ centuries considered man as a dualistic being (biological and social) while emphasizing his social certainty. The human "I" is a mosaic and consists of various pieces of "I" corresponding to the membership of a person in various groups (family, professional, civil, etc.). Therefore, there are as many different "I" in the same person as there are groups of which he was a member and is a member. Each group sets its own rules of conduct, rights, and obligations for its members, subjecting them to discipline, imposing certain interests and beliefs on them, that is, ultimately, consciously and/or unconsciously changing a person in their own image and likeness. It is impossible to get rid of this influence since the behavior of an individual is not determined by personal whim or arbitrariness. It is, ultimately, the result of the influence of the forces of those groups, of which he is a free or involuntary member. Thus, the sociocentric approach considers a person as a product of certain social (group) relations. However, the absolutization of the importance of public relations on the formation of a person does not allow us to accept it as the only true one (Martin, 2007).

\section{The problem of freedom in the context of activity theory}

The activity approach, as well as the analysis of particular theories of activity, should not be considered as "... a simple hanging of the term 'activity' on various phenomena," since the theory of activity is intended to explain the relations of various phenomena and processes that take place in society. In our case - this is the application of the theory of activity to the explanation of the problem of freedom.

Freedom is a social phenomenon that can move from a state of potential possibility to a realized state through activity. That is why the theory of activity is very relevant

XLinguae, Volume 15 Issue 1, January 2022, ISSN 1337-8384, eISSN 2453-711X 
when studying the problem of freedom. Activity is a mode of existence of a social form of movement, a mode of existence of society. A necessary condition for the existence and development of a person, his personality, is activity, that is, the active attitude of a person to the surrounding reality. Through the activity, a person is included in the system of objective social relations, ordering and organizing his behavior in relation to other people. Conscious actions (activities) determine the nature of the duties and the measure of responsibility of the individual to himself and society.

It is worth noting that in methodological terms, there are several approaches to the study of the phenomenon of activity: objective-idealistic (the role of supernatural entities), scientific (as a process of self-movement of objective reality), and materialistic, which restricts activity to the social form of the movement of matter. The activity approach developed by Karl Marx states the following: all social life (allmaterial forms, types of human relations, transformation of human life activity) proceeds from human activity. Thus, social life is the embodiment of human activity, which is considered as a way of existence of the social form of the movement of matter (the way of existence of society). The company acts as a certain set of actions (activities) and their results. The origins of the theory of activity in our country originate in the works of representatives of psychological science. On the basis of Marxist principles, theories of activity were created. In comparison with the psychological understanding, in philosophy, activity was interpreted more broadly: as a form of activity capable of "... unlimited revision and improvement of the underlying programs"; the essence of activity was seen in the creation of the human world by the man himself, who creates his own social relations and himself (Zizek, 2012).

A number of Russian researchers have attempted to systematize the phenomenon of social activity. The structure of social activity is described as goal-means-result. Activity acts as a way of existence of a person as an active being, covering materialpractical, intellectual, and spiritual operations.

The main function of the activity is the preservation and continuous development of society, the creation and improvement of the real human environment (its "second nature"). The concept of activity is based on the consideration of activity as a certain method by which self-movement and self-development of social reality are carried out. The activity can be material and practical, spiritual and theoretical, and sociotechnological. Material and practical activity is a specific relationship between people and nature, which determines the rest of human activities. The spiritual and theoretical activity consists of cognitive, ideological, and value subsystems and sociotechnological activity has incorporated communication, management, and information processes. The substance of all possible elements of social processes can be considered the activity of human individuals organized in stable communities. "...In the entire 'space' of the social, there will not be a single phenomenon that does not represent a certain 'hypostasis' of activity..." (Fromm, 2000). This is the essence of the activity approach to social reality as an explanatory socio-philosophical principle. We accept it as a methodological basis for describing and explaining the object of our research.

The essence of activity is that it is a specifically human form of active (adaptiveadaptive) attitude to the world, a certain type of being in the world. Meaningfully, activity is an expedient change and transformation of the world, and expedient activity of a person, acting as "... self-regulating behavior in the environment of existence, aimed at self-preservation in it by expedient adaptation to its conditions." From the point of view of the system approach, the activity involves a certain structure of elements. As the main structural elements of human activity, there are, for example, the subject, the object, and the activity, which is expressed in a certain way of influencing the object of establishing a communicative interaction. 
Such a "three-link" model of the structure of activity is called by some scientists unreasonably broad, due to the fact that "... the effect of the subject on the object is a substantial property of the subject, that is, the implementation of its inherent activity ability, which is inseparable from the subject...", while the ability to act, which is inherent in the subject and is absent from the object, is not identical to the action itself. The ability to act is a potential opportunity that is realized by being directed at an object.

Thus, it is important for us that the mandatory elements of any action are exclusively the subject and object of this action. The subject can be defined "... as the "initiating side' of the activity, the carrier of the acting ability, with which its triggering and regulatory mechanisms are associated... While the object represents the 'initiated side' of the activity, what the activity capacity of the subject is directed at is absent from the object." Let us clarify that the concepts of subject and object of activity have the property of 'situatedness;' phenomena that reveal the substantial properties of the subject in one situation can change them in another situation to the opposite properties of the object. At the same time, the status of the subject can be unique only to a person or a group of people. In the vast majority of cases, the object of activity is things, objects, and the entire surrounding reality that does not have consciousness. However, in some cases, the object can also be a person who is potentially capable of purposeful, transformative activity but at the moment does not have the opportunity to implement it.

According to some authors, the subject can either act or do nothing. As examples that prove this position, there are cases in which a person passed by a person in distress or, for example, just slept. However, it is worth noting that this position is fundamentally wrong since the activity is a way of existence of the subject, without which it is impossible to imagine it. It simply does not exist. Thus, according to M. Weber, an action is any activity of an individual or individuals who associate their subjective meaning with it. This can also include situations where the action does not involve special efforts to achieve the goal but "comes down to non-interference or patient acceptance." A similar view of activity is also inherent in P. Sorokin, according to which social actions can be not only "active" but also "passive," that is, those that imply "abstinence from external acts" (Schopenhauer, 2013). The analysis of the modern scientific picture of the world leads to the conclusion that the new concept of development in the most concise form is expressed in the form of a three-term formula: consistency, dynamism, self-organization.

Thus, it is recognized that the Universe is the largest system that is only known to science in the first place. Second, it is assumed that open nonequilibrium systems (dissipative systems) cannot exist outside of development and movement. And thirdly, self-organization is a property originally inherent in matter. Synergetics is the natural science basis of the concept of a self-organizing world, studying the processes of selforganization of structures of different nature. Speculative philosophical postulates, according to which matter initially has activity and the desire for structural selforganization, thanks to the synergetic approach, received a new concrete scientific development. So, self-organization is the property of systems to use energy, information, and matter from the outside and activate internal capabilities for the purpose of self-development, which is inherent in all levels of matter, including social systems (Brambo, 2002).

\section{Conclusion}

Life in society presupposes that "the exercise of human and civil rights and freedoms must not violate the rights and freedoms of others." Consequently, the freedom of the subject's activity is always within limits, within the framework of the established legislative order, the absence of which gives rise to arbitrariness and constant 
encroachment on the dignity and property of a person. Sociocultural structures, norms, and laws in society balance the chances of people, limit their selfish self-will, and disregard for the interests of others. Social freedom is possible as equality of chances in the self-realization of people, that is, the creation of conditions for the realization of the potential freedom of each person. The space of personal freedom is enclosed between two limits: the individual is left only to himself, or he is turned to others. Individual freedom has many forms: from absolute freedom, equal to complete loneliness, to absolute unfreedom, identical to the loss of one's self. A person deprived of individual freedom is meaninglessly immersed in a world that is alien to him. He lives not his own but someone else's life. This is a depersonalized personality generated by mass culture, which has turned people into a consumption machine. At the same time, people do not have a feeling of slavery lack of freedom since the life process coincides with the developed desires and ways of satisfying them.

\section{Bibliographic references}

Sen A. (2004). Development as freedom. Moscow. 432 p.

Hayek F. (2006). Law, Legislation and Freedom. Moscow: IRISEN. 644 p.

Brambo, R. S. (2002). Philosophers of ancient Greece. Moscow: Tsentrpoligraf. 320 p.

Levitsky, S. A. (2011). The tragedy of freedom. Minsk: Publishing House of the Belarusian Exarchate. 480 p.

Alekseev, V. Panin, A.V. (2003). Chrestomatiya po filosofii: ucheb. manual / comp. 2nd ed., reprint. and add. Moscow: Prospect. 576 p.

Losev A. F. (2009). History of ancient aesthetics. Early Hellenism. Moscow: Iskusstvo. $815 \mathrm{p}$.

Diogenes of Laertes. (2009). On the life, teachings and sayings of famous philosophers. Moscow: Mysl. 620 p.

Zizek, S. (2012). The Plague of fantasies. Moscow: Humanitarian Center. 388 p.

Selin O. V. (ed.) (2009). The Genius syndrome. Collection of works on the philosophy of genius. Moscow: Algorithm. 288 p.

Rohrmoser, G. (2006). The crisis of liberalism. Moscow: Publishing House of the Institute of Philosophy, Russian Academy of Sciences. 292 p.

Martin M. (Editor). (2007). The Cambridge Companion to Atheism. Cambridge University Press. 320 p.

Zizek, S. (2012). The year of the impossible. The art of dreaming is dangerous. Moscow: Publishing House "Europe". 272 p.

Fromm E. (2000). The spiritual essence of man. The ability to do good and evil. Philos. Nauki (8), 88-95.

Fromm E. (1987). Psychoanalysis and religion. In the book: Twilight of the Gods. Moscow: Politizdat. 217 p.

Schopenhauer A. (2013). The world as will and representation. Moscow.

Words: 6480

Characters: 40783 (22,66 standard pages)

Aralkhanov Baglan

Department of philosophy

L.N. Gumilyov Eurasian National University

st. Satbaev 2, 010000

Nur-Sultan

Kazakhstan

nurbeklunara@mail.ru 
Maldybek Akmaral

Philosophy department

Khoja Akhmet Yassawi International Kazakh-Turkish University,

Bekzat Sattarkhanov avenue, 29

Turkestan city, 020003

Kazakhstan

Amangeldiyev Assan

Department of philosophy

L.N. Gumilyov Eurasian National University

st. Satbaev 2, 010000

Nur-Sultan

Kazakhstan

zurazhan@mail.ru

prof. Almazbek Beishenaliev

Ambassador, Permanent Representative

Avenue Blanc, 51,

1202 Geneva,

Switzerland

Prof. Yessim Garifolla, dr.

Department of philosophy

L.N. Gumilyov Eurasian National University

st. Satbaev 2

Nur-Sultan 010000

Kazakhstan 